\title{
Exploring the Origins of Improved Photocurrent by Acidic Treatment for Quaternary Tantalum-based Oxynitride Photoanodes on the Exam- ple of $\mathrm{CaTaO}_{2} \mathrm{~N}$
}

Zili Ma†, Aleksander Jaworski ${ }^{\ddagger}$ Janine George ${ }^{\perp}$, Anna Rokicinska", Thomas Thersleff ${ }^{\ddagger}$, Tetyana M. Budnyak ${ }^{\ddagger}$, Geoffroy Hautier ${ }^{\perp}$, Andrew J. Pell ${ }^{\ddagger}$, Richard Dronskowski ${ }^{\dagger}$, , Piotr Kuśtrowski", Adam Slabon*,‡

†Chair of Solid-State and Quantum Chemistry, Institute of Inorganic Chemistry, RWTH Aachen University, Landoltweg 1, D-52056 Aachen, Germany

‡Department of Materials and Environmental Chemistry, Stockholm University, Svante Arrhenius väg 16 C, 10691 Stockholm, Sweden

${ }^{\perp}$ Institute of Condensed Matter and Nanosciences, Université Catholique de Louvain, Chemin des Étoiles 8, 1348 Louvain-la-Neuve, Belgium

"Faculty of Chemistry, Jagiellonian University, Gronostajowa 2, 30-387 Krakow, Poland

$\checkmark$ Hoffmann Institute of Advanced Materials, Shenzhen Polytechnic, 7098 Liuxian Blvd, Shenzhen, China

Corresponding author: adam.slabon@mmk.su.se

\section{Table of Content}

\section{Supplementary Figures}

Figure S1. Experimental and simulated powder XRD patterns of $\mathrm{SrNbO}_{2} \mathrm{~N}$ and aqua regia treated $\mathrm{SrNbO}_{2} \mathrm{~N}$ (ICSD 55395).

Figure S2. Experimental and simulated powder XRD patterns of $\mathrm{Ca}_{2} \mathrm{Ta}_{2} \mathrm{O}_{7}$ (ICSD 93847).

Figure S3. Tauc plot for indirect allowed transition for $\mathrm{CaTaO}_{2} \mathrm{~N}$ and $\mathrm{CaTaO}_{2} \mathrm{~N}-\mathrm{A}$.

Figure S4. Solid-state NMR spectra at $60 \mathrm{kHz}$ MAS of ${ }^{1} \mathrm{H}$ for $\mathrm{SrNbO}_{2} \mathrm{~N}$ powder samples before and after aqua regia treatment.

Figure S5. XPS Ta $4 p$ and $\mathrm{N} 1$ s spectra of the $\mathrm{Ti} / \mathrm{CaTaO}_{2} \mathrm{~N}-\mathrm{A} / \mathrm{NiB}_{\mathrm{i}}$ photoanode.

Figure S6. XPS Ta $4 f$ and $\mathrm{Ca} 2 \mathrm{p}$ spectra of the $\mathrm{CaTaO}_{2} \mathrm{~N}$ powder before and after acid treatment. Please note that there is not catalyst coated on the surface.

Figure S7. $\mathrm{LSV}$ of $\mathrm{Ti} / \mathrm{CaTaO}_{2} \mathrm{~N}$-A photoanode without necking treatment.

Figure S8. LSV of FTO/CaTaO ${ }_{2} \mathrm{~N}$ photoanode with necking treatment.

Figure S9. Chronoamperometry (CA) of $\mathrm{Ti} / \mathrm{CaTaO}_{2} \mathrm{~N}$ and $\mathrm{Ti} / \mathrm{CaTaO}_{2} \mathrm{~N}-\mathrm{A}$ photoanode with necking treatment and $\mathrm{NiB}_{\mathrm{i}}$.

\section{Additional Computational Details}




\section{Supplementary Figures}

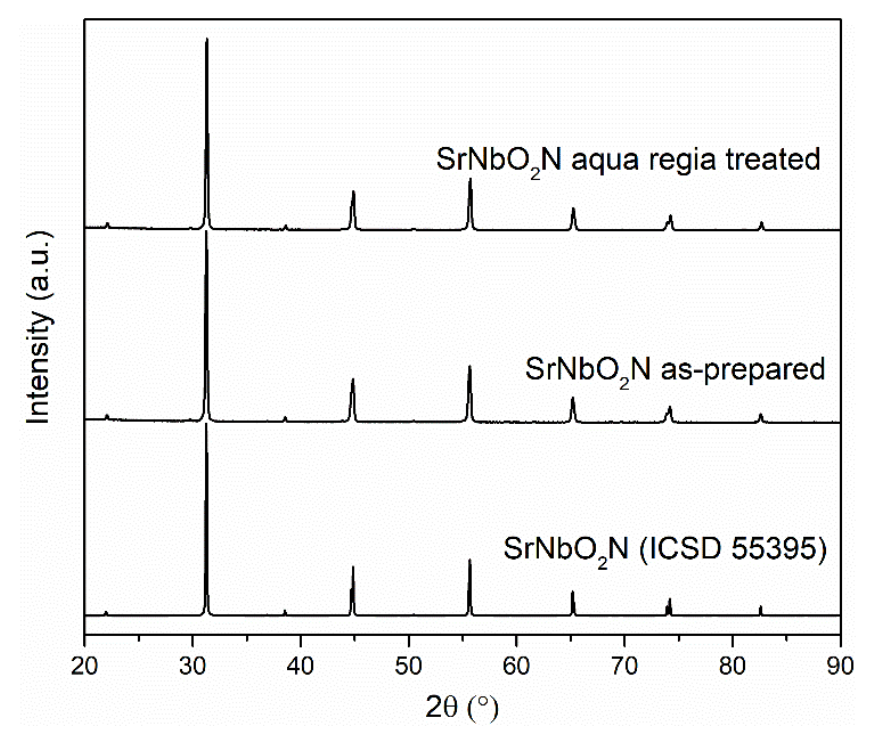

Figure S1. Experimental and simulated powder $\mathrm{XRD}$ patterns of $\mathrm{SrNbO}_{2} \mathrm{~N}$ and aqua regia treated $\mathrm{SrNbO}_{2} \mathrm{~N}$ (ICSD 55395).

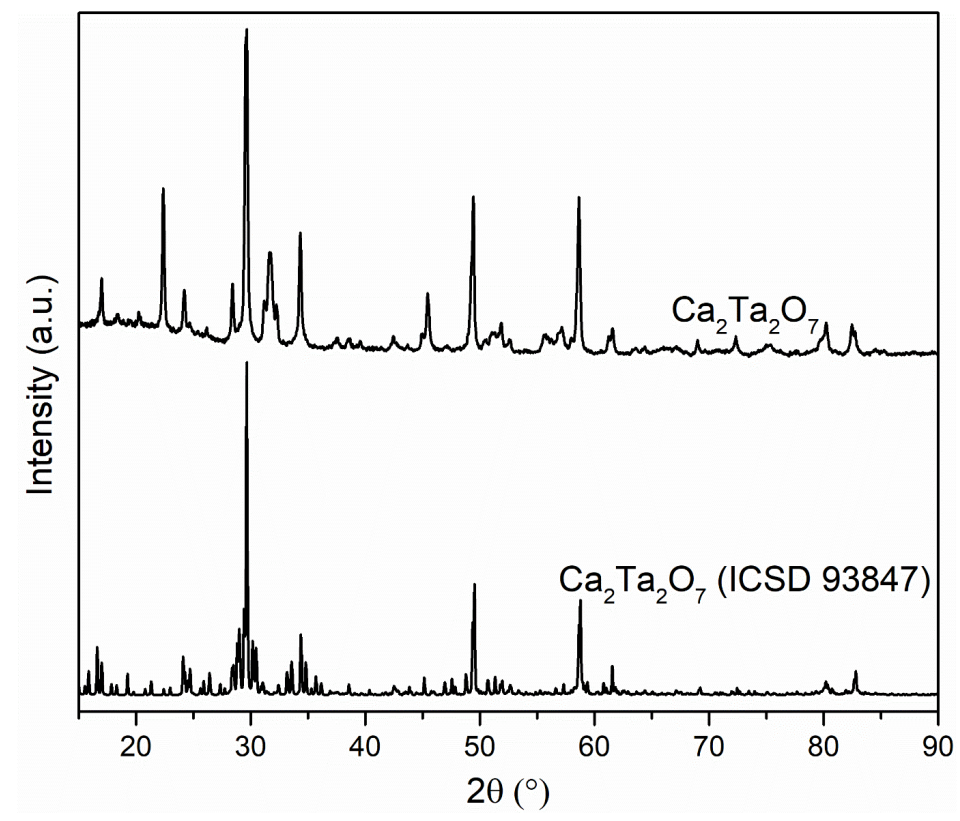

Figure S2. Experimental and simulated powder XRD patterns of $\mathrm{Ca}_{2} \mathrm{Ta}_{2} \mathrm{O}_{7}$ (ICSD 93847). 


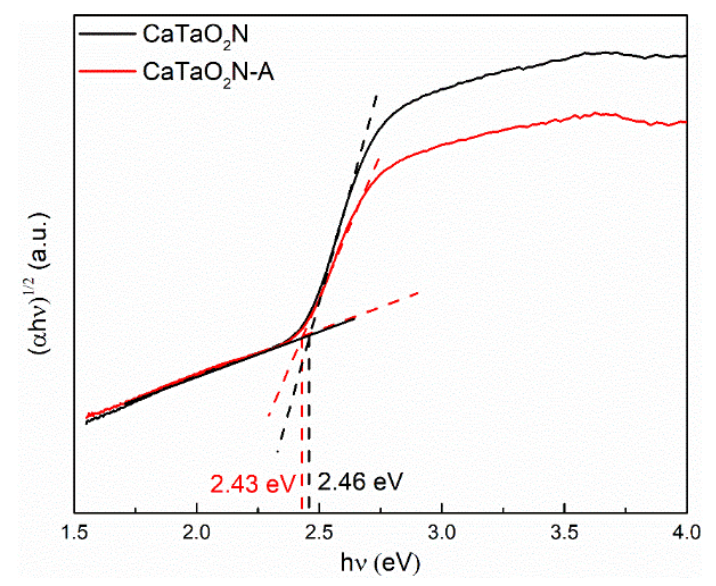

Figure S3. Tauc plot for indirect allowed transition for $\mathrm{CaTaO}_{2} \mathrm{~N}$ and $\mathrm{CaTaO}_{2} \mathrm{~N}-\mathrm{A}$.

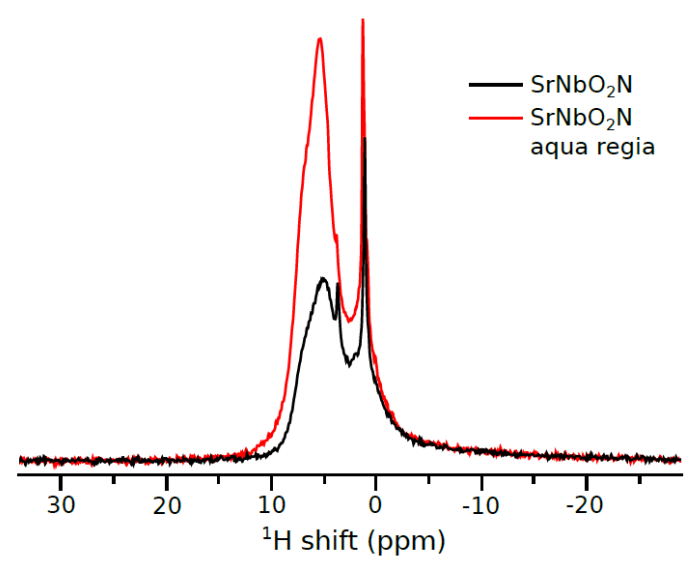

Figure S4. Solid-state NMR spectra at $60 \mathrm{kHz}$ MAS of ${ }^{1} \mathrm{H}$ for $\mathrm{SrNbO}_{2} \mathrm{~N}$ powder samples before and after aqua regia treatment.

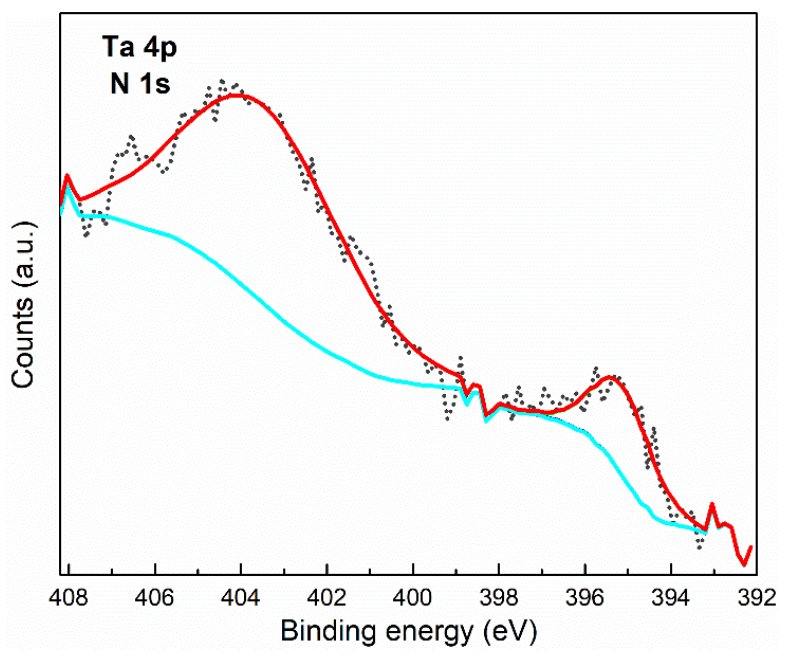

Figure S5. XPS Ta $4 p$ and $\mathrm{N}$ 1s spectra of the $\mathrm{Ti} / \mathrm{CaTaO}_{2} \mathrm{~N}-\mathrm{A} / \mathrm{NiB}_{\mathrm{i}}$ photoanode. 

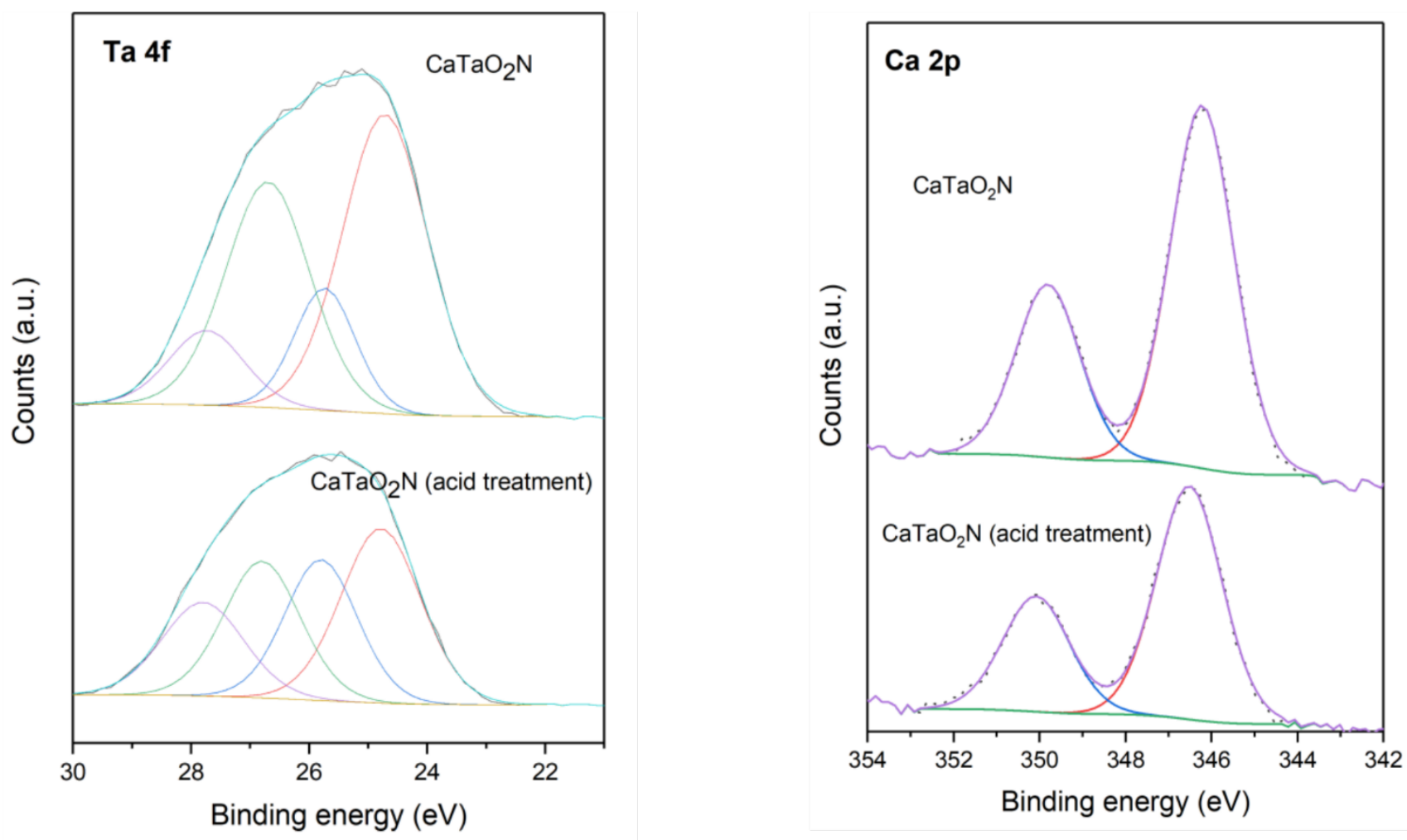

Figure S6. XPS Ta $4 \mathrm{f}$ and $\mathrm{Ca} 2 \mathrm{p}$ spectra of the $\mathrm{CaTaO}_{2} \mathrm{~N}$ powder before and after acid treatment. Please note that there is no catalyst coated on the surface.

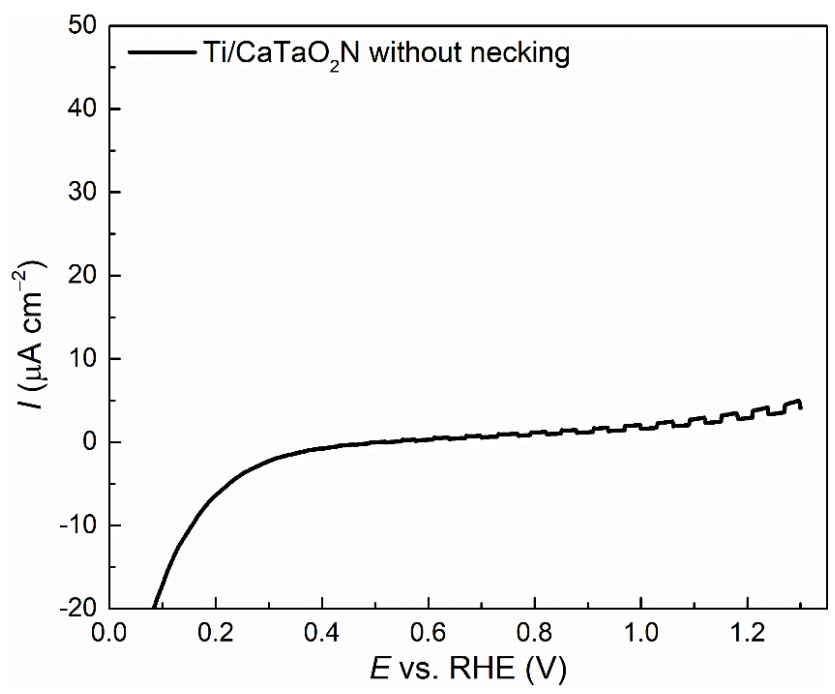

Figure S7. LSV of $\mathrm{Ti} / \mathrm{CaTaO}_{2} \mathrm{~N}-\mathrm{A}$ photoanode without necking treatment. Measurements were performed in $0.1 \mathrm{M} \mathrm{NaOH}$ electrolyte $(\mathrm{pH} 13)$ at a scan rate of $10 \mathrm{mV} \mathrm{s}^{-1}$ under $\mathrm{AM} 1.5 \mathrm{G}$ illumination $\left(100 \mathrm{~mW} \mathrm{~cm}^{-2}\right)$. 


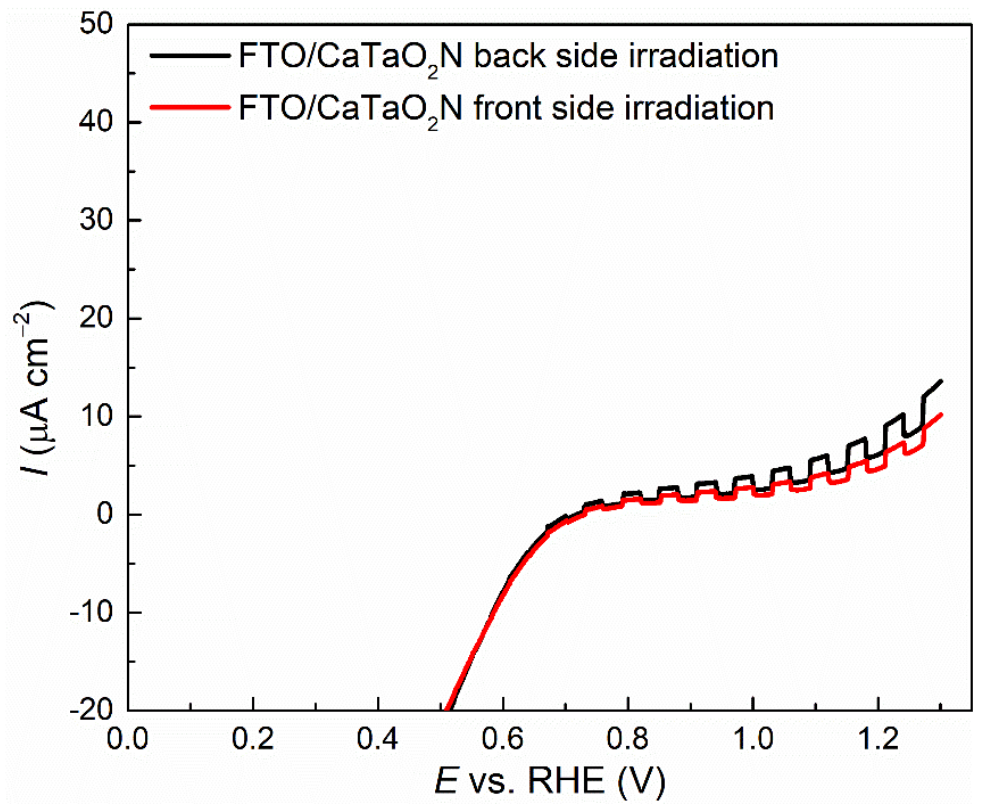

Figure S8. LSV of FTO/CaTaO $\mathrm{C}_{2} \mathrm{~N}$ photoanode with necking treatment. Measurements were performed in $0.1 \mathrm{M} \mathrm{NaOH}$ electrolyte $(\mathrm{pH} \mathrm{13})$ at a scan rate of $10 \mathrm{mV} \mathrm{s}^{-1}$ under AM 1.5G illumination $(100 \mathrm{~mW}$ $\left.\mathrm{cm}^{-2}\right)$.

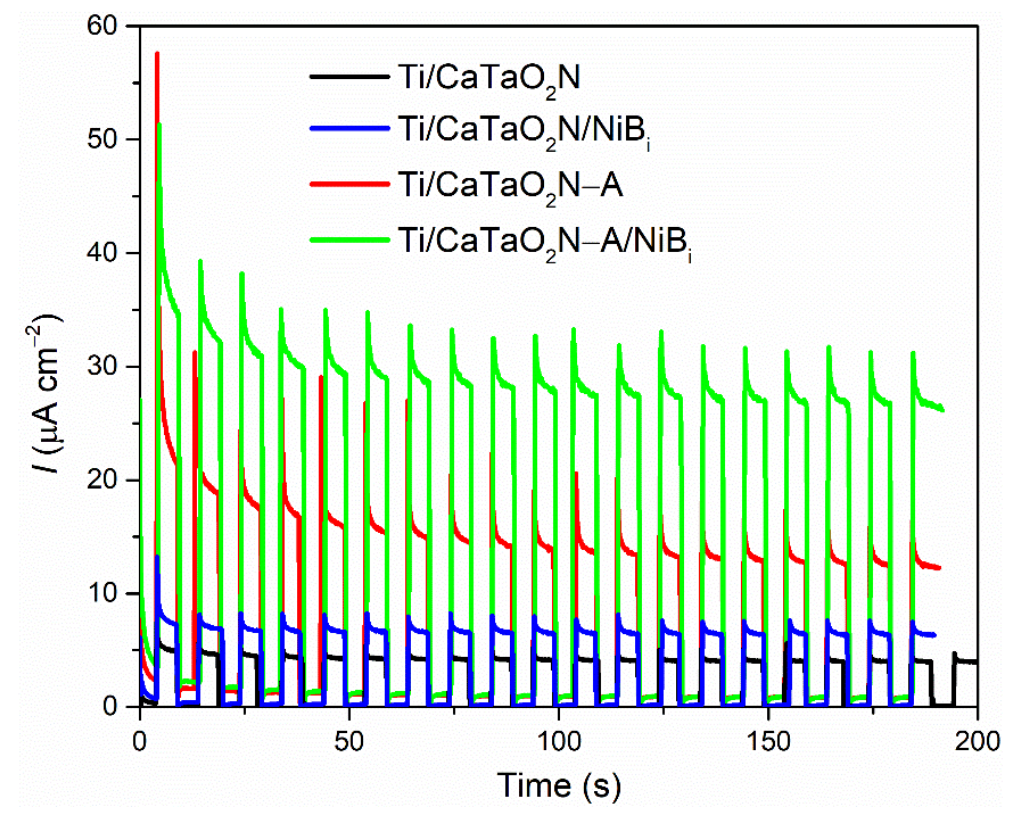

Figure S9. Chronoamperometry $(\mathrm{CA})$ of $\mathrm{Ti} / \mathrm{CaTaO}_{2} \mathrm{~N}$ and $\mathrm{Ti} / \mathrm{CaTaO}_{2} \mathrm{~N}$-A photoanode with necking treatment and $\mathrm{NiB}_{\mathrm{i}}$. Measurements were performed in $0.1 \mathrm{M} \mathrm{NaOH}$ electrolyte $(\mathrm{pH} 13)$ at $1.23 \mathrm{~V}$ vs RHE under chopping AM $1.5 \mathrm{G}$ illumination $\left(100 \mathrm{~mW} \mathrm{~cm}^{-2}\right)$. 


\section{Additional Computational Details}

Additional references for computational experiments were:

i) Kresse, G. and Hafner, J. Ab initio molecular dynamics for liquid metals, Phys. Rev. B, 1993, 47, 558.

ii) Kresse, G, Hafner, J. Ab initio molecular-dynamics simulation of the liquid-metal-amorphoussemiconductor transition in germanium, Phys. Rev. B, 1994, 49, 14251.

iii) Kresse, G., Furthmüller, J. Efficient iterative schemes for ab initio total-energy calculations using a plane-wave basis set. Phys. Rev. B, 1996, 54, 11169.

iv) Kresse, G., Furthmüller, J. Efficiency of ab-initio total energy calculations for metals and semiconductors using a plane-wave basis set. Comput. Mat. Sci. 1996, 6, 15. 